\title{
Photobiomodulation for Gingival Papilla Regeneration: An Innovative Approach
}

\author{
Akhil K Padmanabhan*, Rashmi Paramashiviah, Priyanka Acharya, Prabhuji MLV \\ Department of Periodontology, Krishnadevaraya College of Dental Sciences and Hospital, Bangalore- 562157, \\ Karnataka, India
}

*Corresponding Author: Akhil K Padmanabhan, Department of Periodontology, Krishnadevaraya College of Dental Sciences and Hospital, Bangalore- 562157, Karnataka, India. Email: drakhilkp@gmail.com

\begin{abstract}
The presence or absence of the interproximal papilla is of great concern to periodontists, restorative dentists, and to the patients. The loss of papilla can lead to cosmetic deformities (so-called "black triangle disease"), phonetic problems (space allows passage for the air or saliva), and lateral food impaction. Often the loss of papilla is a consequence of periodontal disease because of gingival inflammation, attachment loss and interproximal bone height resorption. Missing papillae can also result from periodontal surgical therapy, as the soft-tissues usually contract during the healing period. The interdental papilla as a structure with minor blood supply was left more or less untouched by clinicians. Reconstruction of the lost interdental papilla is one of the most challenging and least predictable problem. Several authors have contributed their view points on regenerative aspects of interdental papilla which includes use of growth factors, platelet derivatives, Low level laser therapy etc. Hemolasertherapy is the result of photobiomodulation treatments carried out with blood, wherein the patient's blood drops are used in a given area together with laser PBMT. It intensifies the functioning and reproduction of cells, thus having a gentle yet long lasting and cumulative effect. The aim of this study is to evaluate the effectiveness of an innovative technique called hemolasertherapy, which stimulates growth of interdental papilla and thus permanently fills in the black triangles. Two patients with bilateral Class I papillary recessions were treated with with hemolaser therapy. The photobiomodulation therapy (PBMT) using a $810 \mathrm{~nm}$ diode laser (FOX ARC ${ }^{T M}$ ), contact mode in two steps: before the bleeding (first PBMT) and immediately after bleeding (second PBMT) was performed. There was a significant increase in the papillary height in both the cases treated. The papillary closure obtained in the study were clinically satisfactory showing the effectiveness of hemolasertherapy as a minimally invasive and simple procedure for papilla regeneration.
\end{abstract}

Keywords: Hemolasertherapy, Photobiomodulation, Interdental papilla, Diode Laser, Regeneration

\section{INTRODUCTION}

In recent years, clinician and dentist's esthetic demand in dentistry have increased rapidly, driven by an enhanced awareness of beauty and esthetics. The ultimate goal in modern restorative dentistry is to achieve "white" and "pink" esthetics in esthetically important zones. Loss of gingival tissue, which constitutes interdental papilla, forms what in odontology is called black triangles. [1] It often poses an esthetic challenge to the individual and generates

functional damage besides provoking recurrent gingivitis. [1] The most common reason for papillary loss in the adult population is loss of periodontal support because of plaque-associated lesions. However, abnormal tooth shape, improper contours of prosthetic restorations, an traumatic oral hygiene procedures may also negatively influence the outline of the interdental soft tissues. Today, one of the most challenging aspects of periodontal reconstructive surgery is to obtain a predictable interdental papilla in the esthetic zone.

When two adjacent natural teeth are present, there is supracrestal formation of biologic width. In healthy teeth, the bone crest is separated from the cemento-enamel junction (CEJ) by an average distance of $1 \mathrm{~mm}$.[2] In addition, thebone crest follows the contour of the CEJ, resulting in a scalloped form that is more apical at the facial and lingual aspects of the tooth and peaks ; 2.1 to $4.1 \mathrm{~mm}$ more coronal interproximally, which supports and maintains the papilla interproximally.[3] When the interdental papilla fills the gingival embrasure, 5 $\mathrm{mm}$ of soft tissue is present between the bone crest inter-proximally and the tip of the interdental papilla. This $5 \mathrm{~mm}$ includes $1 \mathrm{~mm}$ supracrestal connective tissue, $1 \mathrm{~mm}$ epithelial 
adherence, and $3 \mathrm{~mm}$ sulcular depth. This anatomical aspect of the interdental papilla makes the regeneration of the papilla difficult unless there is sufficient underlying osseous support and vascularity.

Several surgical and nonsurgical techniques have been proposed to treat soft tissue deformities and manage the interproximal space. The nonsurgical approaches (orthodontic, prosthetic, and restorative procedures modify the interproximal space, thereby inducing modifications to the soft tissues. [4] The surgical techniques aim to recontour, preserve, or reconstruct the soft tissue between teeth and implants. [4]

The literature is prolific in demonstrating the effects of Photobiomodulation therapy (PBMT) at several cell functional levels, such as proliferation, migration, differentiation, protein synthesis and release of growth factors. All of these are crucial for tissue regeneration.

Systematic review on the effect of PBMT on mesenchymal stem cells (MSCs) concluded that it has a positive effect influencing proliferation of the studied stem cells. [5] PBMT improves survival, proliferation, migration, and differentiation of originated dentoalveolar stem cells [5]

However, the effect of biostimulation on papilla regeneration is not well documented and hence this was the emphasis of our case report.

This case report presents a novel minimally invasive and simple technique for regeneration of interdental papilla in natural dentition using photobiomodulation.

\section{MATERIALS AND MethodS}

\section{Case 1}

25 year old male patient with the chief complaint of black spaces between teeth in the anterior region was the subject. On examination the patient presented with bilateral class I and II papillary recession in the maxillary anterior teeth, according to Norland and Tarnovs classification 1998.

\subsection{Pre Procedural Evaluation}

To confirm the patients' periodontal health, a prior evaluation was performed to ensure they had healthy gums i.e. no edema, bleeding, inflammation, or gum retraction. Oral hygiene was evaluated and found to be good. Any systemic disorders/conditions that may alter the outcomes of the procedure were ruled out.

\subsection{Procedure}

\section{First Day}

Preoperative measurements of the interdental papilla from canine to canine was recorded.

Each papillary defect was measured as a triangle with the height measured from the interdental contact point to the tip of the papilla (Figure 1). Base was measured as the distance between the proximal surfaces of the adjacent tooth surfaces at the tip of the papilla (Figure 1).

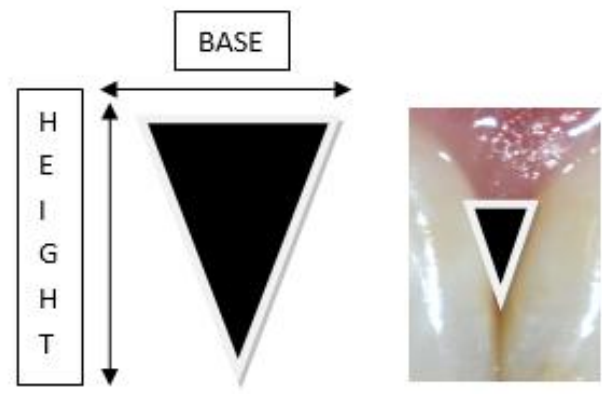

Figure1. The 2 dimensional measurements of the interdental papilla

After the application of topical anesthetic agent, bleeding points were marked on the gingiva with a tissue marker. Three points per tooth, and a point between the labial and lingual papilla as shown in the picture (Figure 2).

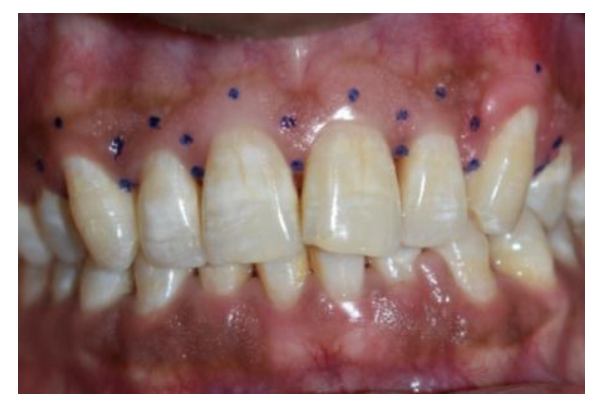

Figure2. Three points marked per papilla for PBMT and for inducing bleeding

PBMT was applied with a diode laser in two stages: Before bleeding (first PBMT) for stimulation of the local microcirculation and immediately after bleeding (second PBMT) to stimulate the stem cells.

Each spot was irradiated with diode laser at a power setting of $100 \mathrm{~mW}$ for 20 seconds/ maximum energy of $2 \mathrm{~J}$ per point (Figure 3 ).

At the base of the papilla, the fiber tip was inserted approximately $3-4 \mathrm{~mm}$ into the interdental papilla and irradiated at the same power setting (Figure 4)

The laser parameters are:

Light source: Low-level diode laser

Active medium: GaAlAs 
Wavelength: $810 \mathrm{~nm}$

Power output: $100 \mathrm{~mW}, \mathrm{CW}$

Irradiation mode: Contact, punctual, in two steps/day

Spot area: $0.19 \mathrm{~cm} 2$

Exposure time per point: $20 \mathrm{sec}$

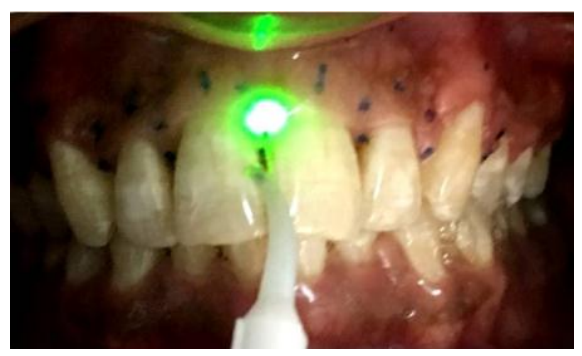

Figure3. Biostimulating the spots marked

Laser biostimulation was used with the purpose of increasing blood microcirculation to promote metabolic improvement and stimulation of fibroblastic activity, to obtain healthy and stable gingival growth in the long term ${ }^{1}$.
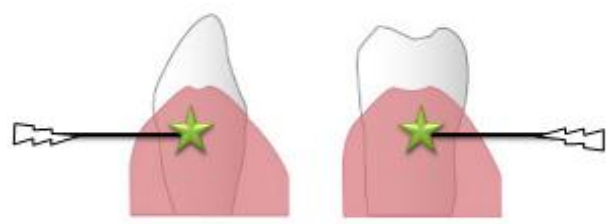

Figure4. Biostimulating the base of the papilla

Pricks were made on the gingiva with explorer tip on every bleeding point marked (Figure-5A \& $5 \mathrm{~B})$. The blood was allowed to flow into the sulcus and the interdental embrasure (Figure- 6).

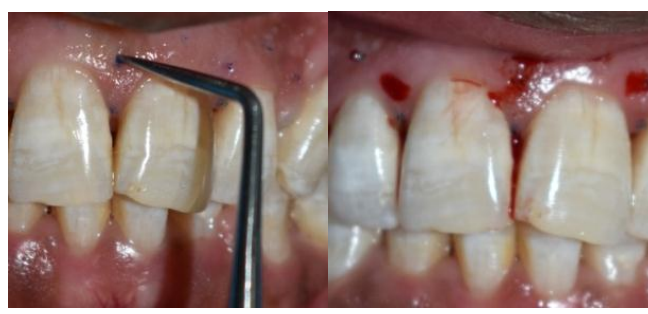

Figure5A. Inducing bleeding spots with explorer, $\mathbf{5 B}$ : bleeding from the spots

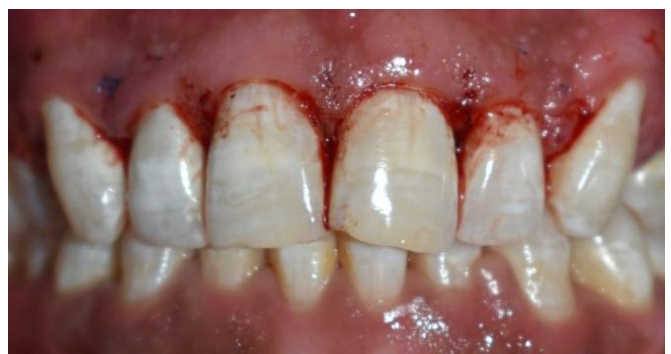

Figure6. The blood is allowed to flow into the embrasure spaces

The bleeding spots were then irradiated with the same power setting.
Patient was then asked to rest on the dental chair for fifteen minutes and then discharged. Patient was recalled after seven days for the second session of hemolasertherapy.

The procedure was carried out on the seventh day also and post operative instructions were given.

The second case was also treated with the same procedure on day one and seven.

\section{Results}

The soft tissue gain in both the cases treated were clinically acceptable. There was a maximum gain in tissue in the interdental papilla between Maxillary central incisors and between right maxillary central incisor and lateral incisor. (Table 1 and Table 2)

Complete closure of the papilla was achieved in between the maxillary left canine and lateral incisor in case one and between the central incisors in case two.

Case- 1

\section{Preoperative Measurements (Day 1)}

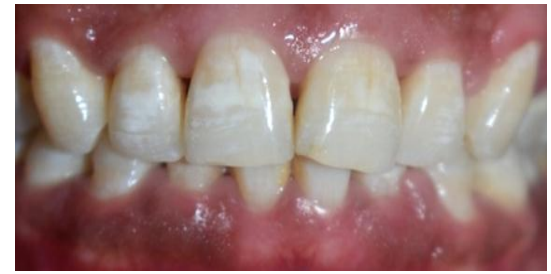

Figure7. Preoperative photograph of the papillary defects on the first day of procedure

\section{Post-Operative Measurements (Day 7)}

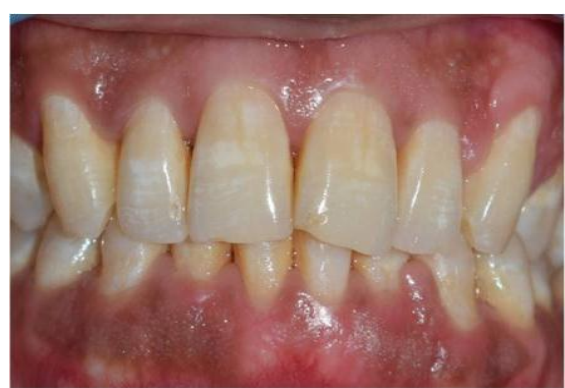

Figure8. Post-operative photograph of the papillary defects on the seventh day after the procedure

\section{Post-Operative Measurements (Day 14)}

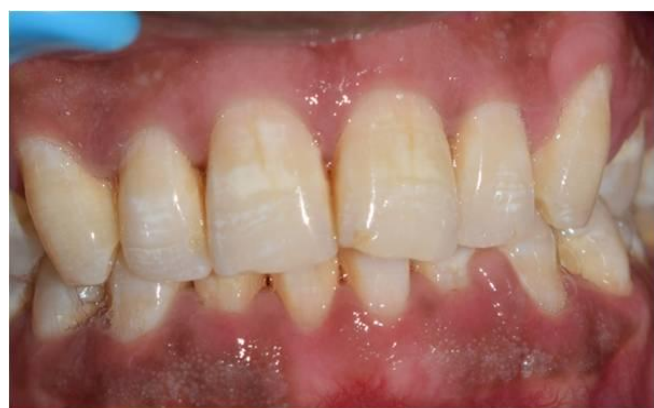

Figure9. Post-operative photograph of the papillary defects on the fourteenth day after the procedure 
Table1. The measurements of the papillary defect on day 1, 7 and 14 (Case 1)

\begin{tabular}{|l|l|l|l|l|l|}
\hline Interdental papilla & $13-12$ & $12-11$ & $11-21$ & $21-22$ & $22-23$ \\
\hline Day 1 & $\mathbf{3 . 0}$ & $\mathbf{2 . 5}$ & $\mathbf{2 . 0}$ & $\mathbf{3 . 0}$ & $\mathbf{1 . 0}^{*}$ \\
& $\mathbf{2 . 5}$ & $\mathbf{2 . 0}$ & $\mathbf{1 . 5}$ & $\mathbf{2 . 0}$ & $\mathbf{1 . 0}$ \\
\hline Day 7 & $1.5^{*}$ & $\mathbf{2 . 0}$ & $\mathbf{0 . 5}$ & $\mathbf{2 . 0}$ & $\mathbf{0}^{*} \mathbf{0}$ \\
& 1.5 & $\mathbf{1 . 0}$ & $\mathbf{0 . 5}$ & $\mathbf{1 . 5}$ & \\
\hline Day 14 & $\mathbf{1 . 5}^{*}$ & $\mathbf{1 . 5}$ & $\mathbf{0 . 5}$ & $\mathbf{1 . 5}^{*}$ & $\mathbf{0}^{*} \mathbf{0}$ \\
& $\mathbf{1 . 0}$ & $\mathbf{1 . 0}$ & $\mathbf{0 . 5}$ & $\mathbf{1 . 0}$ & \\
\hline
\end{tabular}

\section{Preoperative (Day 1)}

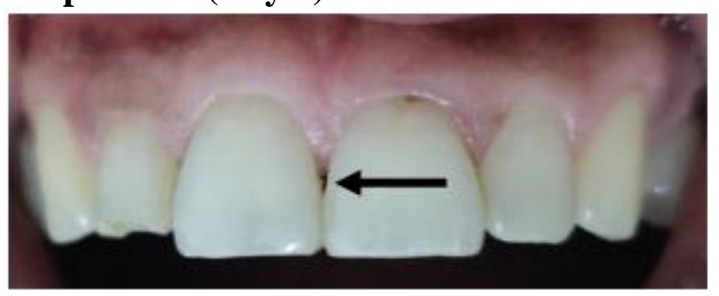

Figure10. Preoperative photograph showing the black triangle with the arrow

\section{Post-Operative (Day 7)}

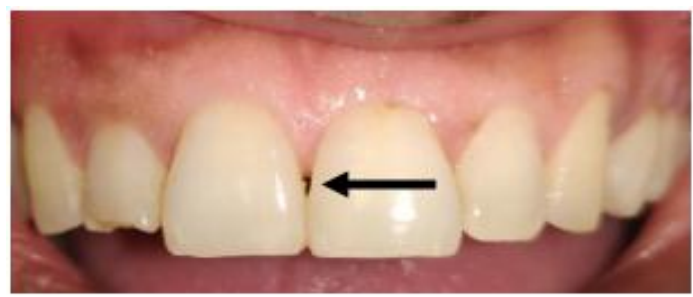

Figure10. Photograph showing a reduction in the black triangle after the first session on the seventh day

\section{Post-Operative (Day 14)}

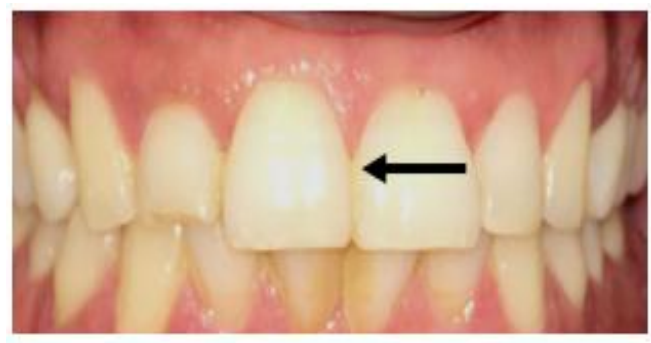

Figure11. Final result showing a complete papillary fill

Table2. The measurements of the papillary defect on day 1, 7 and 14 (Case 2)

\begin{tabular}{|l|l|l|l|l|l|}
\hline Interdental & $13-$ & $12-$ & $11-$ & $21-$ & $22-$ \\
papilla & 12 & 11 & 21 & 22 & 23 \\
\hline Day 1 & $\mathbf{0 . 5}$ & $\mathbf{0}$ & $\mathbf{1 . 0}$ & $\mathbf{0 . 5}$ & $\mathbf{0 . 5}$ \\
& $\mathbf{0 . 5}$ & $\mathbf{0}$ & $\mathbf{1 . 0}$ & $\mathbf{0 . 5}$ & $\mathbf{0 . 5}$ \\
\hline Day 7 & $\mathbf{0 . 5}$ & $\mathbf{0}^{*}$ & $\mathbf{0 . 5}$ & $\mathbf{0 . 5}$ & $\mathbf{0 . 5}$ \\
& $\mathbf{0 . 5}$ & $\mathbf{0}$ & $\mathbf{0 . 5}$ & $\mathbf{0 . 5}$ & $\mathbf{0 . 5}$ \\
\hline Day 14 & $\mathbf{0}$ & $\mathbf{0}^{*}$ & $\mathbf{0}$ & $\mathbf{0 . 5}$ & $\mathbf{0}^{*}$ \\
& $\mathbf{0}$ & $\mathbf{0}$ & $\mathbf{0}$ & $\mathbf{0 . 5}$ & $\mathbf{0}$ \\
\hline
\end{tabular}

\section{DISCUSSION}

Modern dentistry revolves around pink and white. The harmony of pink and white esthetics remains the corner stone of meeting the increasing esthetic demands of the modern era.
Interdental papilla plays a major role in maintaining the pink esthetics and thus beautifying ones smile.

Loss of interdental papilla is a common periodontal problem. One of the most difficult goals in the regeneration of the soft tissues is the reconstruction of interdental papilla. A number of techniques have been tried, but the results still lack predictability. Nonsurgical techniques include repeated curettage of the interdental papilla, orthodontic and restorative correction, and hyaluronic acid application, while surgical techniques include pedicle and free gingival graft, connective tissue grafts, and subepithelial connective tissue graft. [6]

The success depends on the elimination of the etiological factors before papillae can be reconstructed. In 1985, Shapiro advocated a noninvasive approach by inducing proliferation of the gingival tissue after repeated scaling and curettage. [7] Beagle used a combination approach of roll technique and papilla preservation technique. [8] Free soft tissue grafts for papillary augmentation with coronal displacement of the gingival-papillary unit and placement of subepithelial connective tissue graft was described by Han and Takei. [9]

Most of the techniques are invasive and has its own advantages and disadvantages. The introduction of lasers have made revolutionary changes in the field of regenerative medicine. It has been used in the area of soft tissue regeneration on oral surgery and periodontal therapies.

The use of laser by Cranka for the reconstruction of gingival papilla demonstrated good results. [10] The effect of low level diode laser on human gingival fibroblasts have been demonstrated in multiple studies. [11, 12] It is also found that diode laser irradiation can proliferate the stem cells. However, there is no much evidence for the use of diode laser in combination with hemotherapy for regeneration of interdental papilla.

\section{CONCLUSION}

The interdental papilla regeneration has always been a challenge with its unpredictable outcome. 
The techniques employed so far have been surgically complex and invasive. Photo biomodulation as observed is the most simple and non invasive method in esthetic periodontal procedures. The results of this study suggests that photobiostimulation can be an effective, mode of treatment for interdental papilla regeneration and could even be employed in peri implant areas where black triangles are common. Further studies with a larger sample size and long term follow up is required to determine the predictability of this procedure.

\section{REFERENCES}

[1] Zanin F, Moreira MS, Pedroni AC, Windlin M, Brugnera AP, Brugnera Júnior A, Marques MM. Hemolasertherapy: A Novel Procedure for Gingival Papilla Regeneration-Case Report. Photomedicine and laser surgery. $2018 \mathrm{Apr}$ $1 ; 36(4): 221-6$.

[2] Jemt T. Regeneration of gingival papillae after single- implant treatment. Int $\mathrm{J}$ Periodontics Restorative Dent 1997; 17:326-333.

[3] Tarnow DP, Magner AW, Fletcher P. The effect of the distance from the contact point to the crest of bone on the presence or absence of the interproximal dental papilla. J Periodontol 1992;63:995-996.

[4] Prato GP, Rotundo R, Cortellini P, Tinti C, Azzi $R$. Interdental papilla management: a review and classification of the therapeutic approaches. Journal of Prosthetic Dentistry. 2004 Nov 1;92(5):476
[5] Marques MM, Diniz IM, de Cara SP, et al. Photobiomodulatio of dental derived mesenchymal stem cells a systematic review. Photomed Laser Surg 2016;34:500- 508

[6] Sharanappa M, Konuganti K, Kumar A, Rima. Papilla Reconstruction: Reclaiming the Lost! J Health Sci Res 2016;7(1):19-22.

[7] Shapiro A. Regeneration of interdental papillae using periodic curettage. Int $\mathrm{J}$ Periodontics Restorative Dent 1985;5(5): 27-33.

[8] Carranza N, Zogbi C. Reconstruction of the interdental papilla with an underlying subepithelial connective tissue graft: technical considerations and case reports. Int $\mathbf{J}$ Periodontics Restorative Dent 2011 SepOct;31(5):45-50.

[9] Han TJ, Takei HH. Progress in gingival papilla reconstruction. Periodontol 20001996 Jun;11: 65-68

[10] Cranska JP. Laser soft-tissue therapy to regenerate a gingival papilla. Dentistry Today. 2007;26(12):66.

[11] Vinck EM, Cagnie BJ, Cornelissen MJ, Declercq HA, Cambier DC. Increased fibroblast proliferation induced by light emitting diode and low power laser irradiation. Lasers in medical science. 2003 May 1;18(2):95-9.

[12] Kreisler M, Christoffers AB, Al-Haj H, Willershausen B, d'Hoedt B. Low level 809-nm diode laser-induced in vitro stimulation of the proliferation of human gingival fibroblasts. Lasers in Surgery and Medicine: The Official Journal of the American Society for Laser Medicine and Surgery. 2002 Jun;30(5):365-9.

Citation: Akhil K Padmanabhan, Rashmi Paramashiviah, Priyanka Acharya, Prabhuji MLV. Photobiomodulation for Gingival Papilla Regeneration: An Innovative Approach. ARC Journal of Dental science. 2019; 4(2):9-13. doi:dx.doi.org/ 10.20431/2456-0030. 0402003.

Copyright: () 2019 Authors. This is an open-access article distributed under the terms of the Creative Commons Attribution License, which permits unrestricted use, distribution, and reproduction in any medium, provided the original author and source are credited. 